\title{
Analysis of Postural Control in Sitting by Pressure Mapping in Patients With Multiple Sclerosis, Spinal Cord Injury and Friedreich's Ataxia
}

\section{María Mercedes Reguera-García}

Universidad de Leon

Raquel Leirós-Rodríguez ( $\nabla$ rleiros@uvigo.es)

Universidade de Vigo https://orcid.org/0000-0001-7502-7644

Lorena Álvarez-Barrio

Universidad de Leon

Beatriz Alonso-Cortés Fradejas

Universidad de Leon

\section{Methodology}

Keywords: Neurology, Pressure ulcer, Postural balance, Sitting position, Measurement Equipment, Prevention \& control, Physical Therapy Specialty

Posted Date: June 5th, 2020

DOl: https://doi.org/10.21203/rs.3.rs-32856/v1

License: (9) This work is licensed under a Creative Commons Attribution 4.0 International License. Read Full License 


\section{Abstract}

Background: The tools available for the postural control assessment in patients with neurological diseases lack reliability and sensitivity to small changes in patient functionality. The appearance of pressure mapping has allowed quantitative evaluation of postural control in sitting. This study was carried out todetermine the evaluations in pressure mapping and verifying whether they are different between the three sample groups (multiple sclerosis, spinal cord injury and Friedreich's ataxia), and to determine whether the pressure mapping is more sensitive than functional tests.

Methods: A cross-sectional study was carried out in a random sample of 10 adult patients with neurological involvement. The tests applied were: pressure mapping, seated Lateral Reach Test, seated Functional Reach Test, Berg Balance Scale, Posture and Postural Ability Scale, Function in Sitting Test, and Trunk Control Test.

Results: The pressure mapping showed a higher mean pressure in the people with Friedreich's ataxia compared to other groups. The highest values of maximum pressure and the area of contact were found in users with spinal cord injury.

Conclusions: People with different neurological pathologies and similar results in functional tests have very different results in the pressure mapping. The relation between the pressure mapping variables and the functional tests were numerous, especially in the multiple sclerosis group.

\section{Background}

Motor control includes all sensory-motor and cognitive processes, through which the neuro-muscular activities employed in a coordinated movement are coordinated. Thus, it is the integration of all sensory information (both internal and external) to apply the correct combination of muscular solicitation that results in the desired movement. All this requires the coordinated interaction of the nervous and musculoskeletal systems and is essential for the interaction of the individual with the environment, since, in combination with a voluntary movement action, it is crucial to maintain control of posture and balance $(1,2)$.Postural control is a complex skill based on the interaction of sensory-motor processes. The main purpose of postural control is to maintain the postural orientation desired by the individual while resisting, in balance, the force of gravity that acts on his/her body, as well as to orient the position of the body segments, thus allowing the correct perception of environmental stimuli while performing voluntary tasks(3-6).Trunk control has been identified as an important early predictor of the functionality of people with neurological disorders and is considered a prerequisite to maintain balance in sitting and standing, gait and during the simultaneous performance of several tasks $(7,8)$.

Most neurological diseases involve the deterioration of motor control, mainly due to the degeneration or injury of the nervous and neuro-muscular systems. These deficits include the loss of coordination and the difficulty in maintaining static balance and gait $(9,10)$. Movements are often also made less harmonic 
spatially and/or temporarily by modifications of the neuromuscular system. All this reduces the day-today functionality of people with neurological diseases $(11,12)$.

For the correct assessment of postural control, the tools available in the clinical setting lack sufficient reliability and sensitivity to small changes in patient functionality. However, in the laboratory environment there are tools capable of quantifying balance. These are usually devices of high economic cost and difficult accessibility in the daily clinic, although they are very reliable and sensitive $(13,14)$. Taking into account this reality, the evaluation of neurological patients with a high degree of dependence is even more problematic, since, even if there are force platforms, electronic gateways or inertial devices that can quantify the quality of their postural control, these people cannot stand on their own, which is usually the minimum requirement for these devices to perform measurements(15).

However, the appearance of pressure mapping has allowed quantitative evaluation of postural control in sitting. This system evaluates the contact surface of the subjects in a wheelchair, thus providing information on how their positioning is. The use of this tool allows determining which material is more suitable as a seating surface for the individual, providing optimal postural control (within their possibilities) and thus preventing the appearance of pressure ulcers(16). It also allows determining the height and angle of the back of the wheelchair that achieves an optimal pressure distribution(17).

Taking into account all of the above, it was decided to conduct an observational study with neurological people representative of different pathologies that present with postural control disorder (spinal cord injury, multiple sclerosis and Friedreich's ataxia) with the following objectives: (a) determining their evaluations in pressure mapping and verifying whether they are different between the three sample groups, and (b) determining whether the results in pressure mapping are more sensitive than those from the functional tests usually employed in the clinical setting, and verifying whether there is any relationship between the results of both evaluation methods.

\section{Methods}

\subsection{Experimental Design and Sample}

A descriptive and cross-sectional study was carried out in a random sample of adult patients with neurological involvement and the ability to move from the Center for Disability and Dependency CRE of San Andrés del Rabanedo (Spain). This center has 63 users and all of them were invited to participate in the study. A non-probabilistic sampling was carried out by selecting the participants who met the following inclusion criteria: (a) having a confirmed medical diagnosis of Multiple Sclerosis, Friedreich's Ataxia or spinal cord injurythat has forced them to use a wheelchair, and (b) being able to maintain the unsupported control of hands in sitting for at least 10 minutes. Sujetcs were excluded based on the following criteria: (a) being able to stay in standing position with or without the help of external elements, and (b) presence of cognitive impairment (identified by the Mini-Mental State Examination(18). After applying these criteria, the sample consisted of 10 subjects (Figure 1). 
The participants were previously informed of the objectives of the study. If they agreed to participate, in accordance with the Declaration of Helsinki (rev. 2013), all participants signed an informed consent prior to their participation in the study. The institutional review board approved the study protocol and granted the ethical approval from the Ethics Committee of the University of León (code: ETICA-ULE-035-2018).

\subsection{Procedure}

The participants were contacted and summoned for individual evaluation on a single day and with a 5 minute rest interval between each evaluation test. The tests were performed by a physiotherapist previously trained in the evaluation protocol. The evaluation session began with a brief interview in which sociodemographic data (gender, age, weight, height, sitting height, date of neurological diagnosis, and diagnosis of previous and current ulcers) were recorded and the Mini-Mental State Examination was applied. Then, the following functional tests were applied:

- Pressure mapping: The Pressure Imaging System X3Display ${ }^{\circledR}$ (XSENSOR, Canada) is a mapping device capable of monitoring the dispersion of pressure between two contact surfaces through the use of sensors $(16,17)$. The system consists of a thin and flexible pillow enclosed in a nylon fabric of $06 \times 220.98 \mathrm{~cm}$ with a calibration range of $0-256 \mathrm{mmHg}, 1664$ detection points and 3175 spatial resolutions per sensor, a case with housing consisting of electrical components and a liquid crystal display monitor. During the test, the subjects remained in sitting position with their arms crossed to the chest on the pad and their feet resting on the floor. Before recording, the participant was asked to stay on the device for 8 minutes, to allow them to adapt to it. After this adaptation time, the registration was carried out for 2 minutes. Once the pressure was recorded, the session was terminated and the recorded data were saved $(19,20)$. The data were shown as a color-coded map with a numerical value for each of the areas, which reflected the pressure distribution between the surface used and the user. Finally, these data were transferred to a laptop with software Pro V8 to analyze the obtained values of the variables, which were the mean $\left(P_{\text {MEAN }}\right)$, maximum $\left(P_{\text {MAX }}\right)$ and minimum $\left(\mathrm{P}_{\mathrm{MIN}}\right)$ pressures, and contact area of the lift base $(\mathrm{A})$.

- Seated Lateral Reach Test (LRT): this is the variant in sitting position of the Lateral Reach Test that evaluates the postural control of the trunk in the mid-lateral axis. It is performed by arranging the sitting person with the dominant arm extended, $90^{\circ}$ shoulder abduction, the hand closed and the contralateral arm resting on the body. The subjects received the following standardized instructions: they had to move the arm laterally as far as possible, without losing balance in sitting. The hips had to remain fully in contact with the surface of the pressure mapping device and no trunk flexion or rotation was allowed. The maximum perceived position was maintained for three seconds before returning to the starting position. The hand excursion was recorded laterally from the tip of the third finger. A high correlation with the center of body pressure was obtained $(21,22)$.

- Seated Functional Reach Test (FRT): this test evaluates the postural control of the trunk in the anteroposterior axis and has been identified as a useful test to detect deterioration of balance in people 
with disabilities. It is performed starting from a stable sitting position with the arm extended anteriorly, $90^{\circ}$ shoulder flexion and closed hand $(23,24)$.

- Berg Balance Scale (BBS): this scale evaluates postural control with static and dynamic tasks in 14 sections. The tasks that are evaluated are diverse, such as getting up and sitting, sitting without support, transfers, stretching, standing without support, feet together, turning the head back and $360^{\circ}$, stepping up one foot on a step, etc.(25). Although it is an evaluation initially prepared for the elderly, it has been validated for multiple populations(26).

- Posture and Postural Ability Scale (PPAS): this is the modified version of the Postural Ability Scale. It evaluates sitting posture quantitatively (PPAS1) and qualitatively (PPAS2). In a quantitative way, the postural ability is cataloged in 7 levels, depending on whether or not the subject is in a sitting position, with or without support, whether he/she is able to move, transfer weight, recover posture, move or even stand up. Qualitatively, it measures the position of the head, trunk, arms, pelvis, hips, knees and feet in the frontal and sagittal plane, with a score of 0 or 1 when responding with dichotomous answers of "no" and "yes", respectively. This test has shown excellent reliability, high internal consistency and validity of the evaluated construct (posture quality and postural asymmetries) $(27,28)$.

- Function in Sitting Test (FIST): this test evaluates the level of functionality in sitting with 14 tasks (anterior, posterior and lateral thrust and collection of an object that is behind, in front, next to and at the feet of the patient, among other tasks). The total score is 56 points, with each item being assigned a score between 0 and 4 (the higher the score, the less functionality and independence) (29).Although it was initially designed to evaluate the functional sitting balance of people following acute stroke, its validity has been confirmed in other populations(30).

- Trunk Control Test (TCT): it evaluates the control that the subject has over his/her trunk and has been correlated with the degree of functional independence, the symmetry of the center of gravity and the Berg Balance Scale. The items that make up the scale are: rolling to the weak side, rolling to the strong side, sitting up from the lying position and swinging in the sitting position. Each item is assigned a score in the range of 0 (unable), 12 (capable with help) and 25 (independently capable) (31).

\subsection{Statistical analysis}

For the descriptive statistics, the mean was used as a measure of central tendency and the standard deviation as a measure of dispersion.

The Levene test was used to demonstrate the homogeneity of the variance. To verify whether the differences between the groups were significant, the analysis of variance (ANOVA) was used with the Bonferroni correction.

To determine the normality of the variables, the Shapiro-Wilk test was performed, due to the sample size ( $\mathrm{N}$ less than 30 ). To test the hypothesis of equality of means, a single factor ANOVA was used for the 
variables in which the hypothesis of normal distribution (pressure, area) was accepted. The Fisher statistic was applied due to the fact that the $P$ value was higher than 0.05 for the homogeneity of the variances in the Levene's test. To compare the groups one by one, the Tukey post-hoc test was used.

The Kurskal-Wallis non-parametric $\mathrm{H}$ test was used to test the equality hypothesis between the groups of variables in which the normal distribution hypothesis (maximum pressure and minimum pressure) was not rejected.

To determine whether there was a correlation between the quantitative variables of the study, the Pearson and Spearman coefficients were used according to the type of distribution assumed for each of the variables.

All statistical techniques were applied with SPSS software version 23.0 and with the significance level set at $p<0.05$.

\section{Results}

The sample consisted of 10 subjects, with $40 \%$ women and $60 \%$ men, and a mean age of $50.4 \pm 7.3$ years. Subjects with multiple sclerosis accounted for $20 \%$ of the sample ( 2 women), those with Friedreich's ataxia represented 40\% ( 2 women and 2 men) and those with spinal cord injury corresponded to $40 \%$ (4 men).

Table 1 shows the descriptive values of characterization, functional tests and pressure mapping of the total sample and by groups. The results obtained in the functional tests revealed a gigher deterioration of postural control in the group of people with multiple sclerosis, who showed the lowest score (except in FIST and FRT). Higher results were observed in the Friedreich's ataxia group with respect to the spinal cord injury group. 
Table 1

Descriptive statistics of the sample and by groups

\begin{tabular}{|c|c|c|c|c|}
\hline & $\begin{array}{l}\text { All } \\
(n=10)\end{array}$ & $\begin{array}{l}\text { Multipe sclerosis } \\
(n=2)\end{array}$ & $\begin{array}{l}\text { Friedreich's ataxia } \\
(\mathrm{n}=4)\end{array}$ & $\begin{array}{l}\text { Spinal cord injury } \\
(n=4)\end{array}$ \\
\hline Age (years) & $49 \pm 9.2$ & $57 \pm 4.2$ & $49.3 \pm 8.9$ & $44.8 \pm 10.1$ \\
\hline Height (cm) & $\begin{array}{l}168.7 \pm \\
10.7\end{array}$ & $160 \pm 11.3$ & $165.6 \pm 7.9$ & $176.3 \pm 9.9$ \\
\hline Sitting height (cm) & $80 \pm 7.3$ & $71 \pm 0$ & $77 \pm 3.5$ & $87.5 \pm 2.4$ \\
\hline Weight (kg) & $\begin{array}{l}67.8 \pm \\
11.6\end{array}$ & $61.1 \pm 1.3$ & $68.1 \pm 10.8$ & $70.9 \pm 15.7$ \\
\hline $\mathrm{BMI}\left(\mathrm{kg} / \mathrm{m}^{2}\right)$ & $\begin{array}{l}24.4 \pm \\
3.16\end{array}$ & $24 \pm 2.8$ & $24.7 \pm 1.8$ & $24.22 \pm 4.9$ \\
\hline $\begin{array}{l}\text { Duration of disease } \\
\text { (years) }\end{array}$ & $\begin{array}{l}20.3 \pm \\
1.2\end{array}$ & $19.5 \pm 3.5$ & $35.2 \pm 10$ & $8.2 \pm 4.8$ \\
\hline Previous ulcers (n) & $1.6 \pm 0.5$ & $1 \pm 0$ & $2 \pm 0$ & $1.5 \pm 0.6$ \\
\hline Current ulcers (n) & $1.8 \pm 0.4$ & $2 \pm 0$ & $1.8 \pm 0.5$ & $1.8 \pm 0.5$ \\
\hline MMSE (points) & $\begin{array}{l}27.4 \pm \\
4.2\end{array}$ & $21.5 \pm 6.4$ & $29.8 \pm 0.5$ & $28.4 \pm 2.6$ \\
\hline LRT (cm) & $\begin{array}{l}14.7 \pm \\
11.5\end{array}$ & $6.8 \pm 1.8$ & $24.9 \pm 11.9$ & $8.5 \pm 4.8$ \\
\hline \multirow{2}{*}{$\begin{array}{l}\text { FRT (cm) } \\
\text { BBS (points) }\end{array}$} & $\begin{array}{l}24.9 \pm \\
16.9\end{array}$ & \multirow{2}{*}{$\begin{array}{l}16.5 \pm 4.9 \\
5.5 \pm 0.7\end{array}$} & \multirow{2}{*}{$\begin{array}{l}38.7 \pm 13.6 \\
9.3 \pm 2.9\end{array}$} & \multirow{2}{*}{$\begin{array}{l}15.3 \pm 15.4 \\
15.3 \pm 11.1\end{array}$} \\
\hline & $\begin{array}{l}10.9 \pm \\
7.7\end{array}$ & & & \\
\hline PPAS1 (points) & $9.8 \pm 4$ & $6 \pm 8.5$ & $10.5 \pm 3$ & $11 \pm 2$ \\
\hline PPAS2 (scale) & $5.4 \pm 1.2$ & $4.5 \pm 0.7$ & $6 \pm 0$ & $5.2 \pm 1.7$ \\
\hline FIST (points) & $\begin{array}{l}35.5 \pm \\
11.8\end{array}$ & $37.5 \pm 3.5$ & $42.8 \pm 1.9$ & $27.3 \pm 15.7$ \\
\hline TCT (points) & $\begin{array}{l}66.2 \pm \\
24.1\end{array}$ & $55 \pm 8.5$ & $74.3 \pm 20.8$ & $71.3 \pm 33.2$ \\
\hline \multicolumn{5}{|c|}{$\begin{array}{l}\text { BMI: Body Mass Index; MMSE: Mini-Mental State Examination; LRT: Seated Lateral Reach Test; FRT: } \\
\text { Seated Functional Reach Test; BBS: Berg Balance Scale; PPAS1: Posture and Postural Ability Scale } \\
\text { Quantitative; PPAS2: Posture and Postural Ability Scale Qualitative; FIST: Function in Sitting Test; } \\
\text { TCT: Trunk Control Test. }\end{array}$} \\
\hline
\end{tabular}

The pressure mapping results (Table 2 and Figure 2) showed a higher $P_{\text {MEAN }}$ in the people with Friedreich's ataxia $(52.3 \pm 3.9)$ compared to those with multiple sclerosis $(41.7 \pm 5.7)$ and spinal cord injury $(41.3 \pm 3.2)$. This was the only variable extracted from the pressure mapping analysis to provide 
statistically different results among the three groups studied. Specifically, the data showed differences in people with Friedreich's ataxia compared to those diagnosed with multiple sclerosis $(p=0.04)$ and spinal cord injury $(p=0.01)$, with no significant differences between the latter two. However, the highest values of $P_{\text {MAX }}$ and $A$ were found in users with spinal cord injury, with $P_{M A X}=251.5 \pm 8.9 \mathrm{mmHg}$, and $A=1146.9$ $\pm 283.4 \mathrm{mmHg}$, although without statistically significant differences with the other two groups of pathologies. These differences can be seen in Figure 2.

Table 2

Results of the blanket of pressures by groups and comparison between them

\begin{tabular}{|c|c|c|c|c|}
\hline & $\begin{array}{l}\text { All } \\
(n=10)\end{array}$ & $\begin{array}{l}\text { Multipe } \\
\text { sclerosis } \\
(n=2)\end{array}$ & $\begin{array}{l}\text { Friedreich's ataxia } \\
(\mathrm{n}=4)\end{array}$ & $\begin{array}{l}\text { Spinal cord injury } \\
(n=4)\end{array}$ \\
\hline $\mathrm{P}_{\text {MEAN }}(\mathrm{mmHg})$ & $45,8 \pm 6,6$ & $41,7^{(\dagger)} \pm 5,7$ & $52,3^{*} \# \pm 3,9$ & $41,3^{\#} \pm 3,2$ \\
\hline $\mathrm{P}_{\text {MAX }}(\mathrm{mmHg})$ & $239,4 \pm 33,6$ & $204,7 \pm 72,6$ & $244,5 \pm 22,9$ & $251,5 \pm 8,9$ \\
\hline $\mathrm{P}_{\mathrm{MIN}}(\mathrm{mmHg})$ & $10,2 \pm 0,2$ & $10,1 \pm 0,1$ & $10,3 \pm 0,2$ & $10,1 \pm 0,9$ \\
\hline $\mathrm{A}\left(\mathrm{cm}^{2}\right)$ & $\begin{array}{l}1095,3 \pm \\
208,5\end{array}$ & $1036,7 \pm 310,8$ & $1073 \pm 106,7$ & $1146,9 \pm 283,4$ \\
\hline \multicolumn{5}{|c|}{$\mathrm{P}_{\text {MEAN }}$ : Mean pressure; $\mathrm{P}_{\mathrm{MAX}}$ : Maximum pressure; $\mathrm{P}_{\mathrm{MIN}}$ : Minimum pressure; $\mathrm{A}$ : contact area. } \\
\hline
\end{tabular}

Table 3 shows the intragroup analysis data of the correlations between the pressure mapping variables and the functional tests. In the multiple sclerosis group, there were significant positive correlations between $\mathrm{P}_{\text {MEAN }}$ and LRT, FRT and PPAS2 $(r=1, p=0.01)$, and a negative correlation between $\mathrm{P}_{\text {MEAN }}$ and TCT $(r=-1, p=0.01)$. In this group, A was also negatively correlated with LRT, FRT and PPAS2 $(r=1, p=0.05)$, and A was positively correlated with TCT $(r=1 ; p=0.01)$. In the Friedreich's ataxia group, $P_{\text {MIN }}$ was significantly correlated with LRT and FRT ( $r=1 ; p=0.01$, for both) and with TCT $(r=-1 ; p=0.04)$. Finally, in the group of people with spinal cord injury, $\mathrm{P}_{\mathrm{MAX}}$ and PPAS1 were positively correlated $(r=1 ; p=0.05)$. 
Table 3

Significant correlations between pressure mapping and functional tests by groups [ $r$ value (statistical test)]

Table 3. Significant correlations between pressure mapping and functional tests by groups $[r$ value (statistical test)]
$P_{\text {MEAN }}$
$P_{\text {MAX }}$
$P_{\text {MIN }}$
A

\section{Multiple sclerosis}

$\begin{array}{lll}\text { LRT } & 1 * *(\text { Pearson }) & -1 * *(\text { Pearson }) \\ \text { FRT } & 1 * *(\text { Pearson }) & -1 * *(\text { Pearson }) \\ \text { PPAS2 } & 1 * *(\text { Pearson }) & -1 * *(\text { Pearson }) \\ \text { TCT } & -1 * *(\text { Pearson }) & 1 * *(\text { Pearson })\end{array}$

\section{Friedreich's ataxia}

LRT

FRT

TCT $1^{\star \star}($ Spearman $)$

$1 * \star($ Spearman $)$

$-0,96 *$ (Pearson)

\section{Spinal cord injury}

PPAS1

1 (Spearman)

$\mathrm{P}_{\text {MEAN }}$ : Mean pressure; $\mathrm{P}_{\text {MAX }}$ : Maximum pressure; $\mathrm{P}_{\text {MIN }}$ : Minimum pressure; $\mathrm{A}$ : contact area.

LRT: Seated Lateral Reach Test; FRT: Seated Functional Reach Test; PPAS2: Posture and Postural Ability Scale Qualitative; TCT: Trunk Control Test; PPAS1: Posture and Postural Ability Scale Quantitative.

$P$ value: ${ }^{*} p<0.05 ;{ }^{*} p<0.001$

\section{Discussion}

The main objectives of this study were to evaluate pressure mapping in multiple sclerosis, Friedreich's ataxia and spinal cord injury, identifying possible differences between them, and determine the existence of relationship between the results of pressure mapping and those of the functional tests that are most widely used in rehabilitation. Once the results were analyzed, only the $\mathrm{P}_{\text {MEAN }}$ variable provided sufficiently different values between the three pathologies. Therefore, this variable was the only one capable of differentiating between the three subgroups of the sample. In addition, this variable shows that the behavior of sedentary people who are diagnosed with multiple sclerosis and spinal cord injury was significantly different from that of people diagnosed with Friedreich's ataxia. Furthermore, it was observed that the highest number of relationships occurred between pressure mapping and functional tests in the multiple sclerosis group. 
The values obtained by pressure mapping in this study differ from those previously obtained in other investigations, such as that of Berthold et al.(32), we obtained lower values in $\mathrm{P}_{\text {MEAN }}$ and higher in $\mathrm{P}_{\text {MAXX }}$. On the other hand, those authors stated that the $\mathrm{P}_{\text {MEAN }}$ value should not exceed the clinically accepted limit of $32 \mathrm{mmHg}$, and that a $\mathrm{P}_{\text {MAX }}$ of $200 \mathrm{mmHg}$ is too high. This shows that the three populations of our study are above the reference values in both variables.

The reviewed literature shows that $\mathrm{P}_{\text {MEAN }}$ and $\mathrm{P}_{\text {MAX }}$ are the ones that provide more information about the distribution of pressure in sitting. Crawford et al.(33) and Stinson et al.(34)only analyzed the values of $P_{\text {MEAN }}$ and $P_{\text {MAX }}$, since these show the most significant differences between severely disabled people with pathologies such as multiple sclerosis, spinal cord injury and stroke. However, this is not in line with the results obtained in this study, since $\mathrm{P}_{\text {MEAN }}$ and $A$ also showed statistically significant and clinically more sensitive results than the functional tests used in the multiple sclerosis and Friedreich's ataxia subgroups. Despite this, and in accordance with the literature published to date, $\mathrm{P}_{\text {MEAN }}$ is the key variable.

Consequently, it should be interpreted as a fundamental parameter for the design and evaluation of specific treatments for people with these pathologies.

With respect to the protocol used to record pressure mapping, it consisted in 8 minutes of adaptation and 2 minutes of recording. This distribution of times is based on previous studies $(20,33)$,which postulated that, before recording the data, the subject must spend some time on the device in order to adapt to it, verifying that the ideal duration is 8 minutes, and that the 2-minute duration of the test means that reliable information is obtained, especially with people in wheelchairs with multiple sclerosis(33).

Regarding the functional tests, relevant differences were found in the test results by pathology and in comparison with other authors. In LRT, the normal value is 17 centimeters(21). In this test, values below the normal range were obtained in the group with multiple sclerosis and spinal cord injury, which is far from the results obtained by Freeman et al.(22) and Choe et al.(24)in people with Friedreich's ataxia, which were within the normal ranges (no background was found in the scientific literature for these results in people with this pathology).

In FRT, the normal value in the age range of 41-69 years is between 35.1-38.1 centimeters(23).Similarly, values below normal were obtained in people with multiple sclerosis and spinal cord injury, which is far from the results of the studies of Frzovic et et al.(35) andKizony et al.(36). In people with Friedreich's ataxia, a value was achieved within the normal ranges (no background in the scientific literature was found). In FST, the total score was 56 points(29). The data obtained in the multiple sclerosis and spinal injury groups were also below the values reported by previous studies $(37,38)$.Finally, in TCT, the total score was 100 points(39). The data obtained in the multiple sclerosis and spinal injury groups were below the data collected in previous studies $(40,41)$. From the results obtained in the literature review of the functional tests, it is clear that the authors studied people with the same pathologies, although probably with a lower degree of disability and severity in the development of the characteristic symptomatology of these diseases. 
In BBS, our populations obtained ratings between 5.5 and 15.5 points. These scores are lower than the average scores obtained byDowns et al.(26), Eftekharsadat et al.(42)(in people with multiple sclerosis) and Santos de Olivera et al.(43)(in patients with spinocerebellar ataxia).However, our results are similar to those of such studies in people with spinal cord injury. It is evident that our sample obtained lower values due to the fact that they were populations that cannot walk or stand. This condition significantly affects the score on that scale.

As expected in PPAS, a validated test for persons with cerebral palsy(27), our results in the pathologies studied cannot be compared with those of other authors, as there are no previous studies available in the literature. The study populations achieved better values in postural quality quantification than the standards for this tool.

In FIST, our data show that sedentary control was lower compared to the populations of multiple sclerosis(38)and non-ambulatory individuals with spinal cord injury(37).In TCT, this behavior was also observed $(40,41)$. These results suggest that our population is severely affected.

Finally, the differences between the functional tests and pressure mapping, there were few but very strong correlations. In the three subgroups studied, the correlations between the pressure mapping variables and the functional tests were more numerous, especially in the multiple sclerosis group. Similarly, the functional measures recorded in the same starting position (sitting) were more strongly related to the recordings of pressure mapping in sitting. It is worth highlighting the behavior of $A$ in LRT and FRT, which demonstrates that when the subject's contact area in pressure mapping is lower, the scores in LRT and FRT are higher, whereas $\mathrm{P}_{\text {MEAN }}$ increases when the LRT and FRT scores are higher. These correlations found make clear reference to the fact that the construct evaluated by pressure mapping is the state of the postural trunk control.

The main limitation of this work was the small sample size, which was due to the fact that they were people with a serious disability and dependence in the same care center. Likewise, the novelty of the subject and the wide possibilities for future research in this field must be recognized to contribute to the development of the assistance services, which directly affects the improvement of the quality of life of people with serious disabilities and dependence. That is, the approach of specific physiotherapy protocols should be pursued taking into account the status of people with multiple sclerosis, Friedreich's ataxia and spinal cord injury.

In addition, the study of pressures in sitting should be addressed with the use of cushions and at different angles of inclination of the back of the wheelchair to determine whether these modifications significantly reduce the pressure and if this correlates with a lower appearance of ulcers.

\section{Conclusions}

People with different neurological pathologies and similar results in functional tests have very different results when evaluated with pressure mapping. This suggests that, despite being neurological 
pathologies with postural control problems, they do not behave in a uniform manner and, therefore, require specific treatment approaches.

The high pressures detected by pressure mapping show the problems in the postural control of the analyzed individuals and the urgent need for measures that reduce the risk of pressure ulcers.

\section{List Of Abbreviations}

$\mathrm{P}_{\text {MEAN }}$ : mean pressure.

$\mathrm{P}_{\mathrm{MAX}}:$ maximum pressure.

$\mathrm{P}_{\mathrm{MIN}}$ : minimum pressure.

A: area.

LRT: Lateral Reach Test.

FRT: Functional Reach Test.

BBS: Berg Balance Scale.

PPAS:Posture and Postural Ability Scale.

PPAS1: Quantitative Posture and Postural Ability Scale.

PPAS2: Qualitative Posture and Postural Ability Scale.

FIST: Function in Sitting Test.

TCT: Trunk Control Test.

\section{Declarations}

\section{Ethics approval and consent to participate:}

All procedures performed in studies involving human participants were in accordance with the ethical standards of the Ethics Committee of the University of León (Spain; number ETICA-ULE-035-2018) and with the 1964 Helsinki declaration and its later amendments or comparable ethicalstandards. All participants submitted the written informed consent prior to the start of the procedure.

\section{Consent for Publication:}

Not applicable. 


\section{Availability of data and material:}

The database used to carry out this work is in the possession of the authors and will be provided to whoever requests it.

\section{Competing interests:}

No financial or non-financial benefits have been received or will be received from any party related directly or indirectly to the subject of this article.

\section{Funding:}

The authors do not have relevant financial relationships to disclose.

\section{Authors' contributions:}

M.M.R.G., R.L.R, L.A.B., and B.A.C.F. conceptualized and designed the study, drafted the initial manuscript, designed the data collection instruments, collected data, carried out the initial analyses, and critically reviewed the manuscript for important intellectual content. All authors approved the final manuscript as submitted and agree to be accountable for all aspects of the work.

\section{Acknowledgements:}

To the direction of the Center and the Physiotherapy service of the Center for Disability and Dependency Center of San Andres del Rabanedo (León).

\section{References}

1. (1) Rose DJ, Christina RW. A Multilevel Approach to the Study of Motor Control and Learning. Boston: Pearson Education; 2006.

2. (2) Shumway-Cook A, Woollacott MH. Motor Control: Theory and Practical Applications. Londo: Lippincott Williams \& Wilkins; 1995.

3. (3) Massion J. Postural control system. Curr Opin Neurobiol 1994;4(6):877-887.doi:10.1016/09594388(94)90137-6

4. (4) Horak FB, Kluzik J, Hlavacka F. Velocity dependence of vestibular information for postural control on tilting surfaces. J Neurophysiol 2016;116(3):1468-1479.doi:10.1152/jn.00057.2016

5. (5) Ting LH. Dimensional reduction in sensorimotor systems: a framework for understanding muscle coordination of posture. Prog Brain Res 2007;165:299-321. doi:10.1016/S0079-6123(06)65019-X 
6. (6) Karnath HO, Ferber S, Dichgans J. The neural representation of postural control in humans. Proc Natl Acad Sci USA 2000;97(25):13931-13936.doi:10.1073/pnas.240279997

7. (7) Cabanas-Valdés R, Cuchi GU, Bagur-Calafat $C$. Trunk training exercises approaches for improving trunk performance and functional sitting balance in patients with stroke: a systematic review. NeuroRehabilitation 2013;33(4):575-592.doi:10.3233/NRE-130996

8. (8) Haruyama K, Kawakami M, Otsuka T. Effect of core stability training on trunk function, standing balance, and mobility in stroke patients: A randomized controlled trial. Neurorehabil Neural Repair 2017;31(3):240-249.doi:10.1177/1545968316675431

9. (9) Seidler RD, Alberts JL, Stelmach GE. Changes in multi-joint performance with age. Motor Control 2002;6(1):13-19.doi: 10.1123/mcj.6.1.19

10. (10) Seidler RD, Bernard JA, Burutolu TB, Fling BW, Gordon MT, Gwin JT, et al. Motor control and aging: links to age-related brain structural, functional, and biochemical effects. Neurosci Biobehav Rev 2010;34(5):721-733.doi: 10.1016/j.neubiorev.2009.10.005

11. (11) Alexander BH, Rivara FP, Wolf ME. The cost and frequency of hospitalization for fall-related injuries in older adults. Am J Public Health 1992;82(7):1020-1023.doi:10.2105/AJPH.82.7.1020

12. (12) Faulkner JA, Larkin LM, Claflin DR, Brooks SV. Age-related changes in the structure and function of skeletal muscles. Clin Exp Pharmacol Physiol 2007;34(11):1091-1096.doi:10.1111/j.14401681.2007.04752.x

13. (13) Mancini M, Horak FB. The relevance of clinical balance assessment tools to differentiate balance deficits. Eur J Phys Rehabil Med 2010;46(2):239-248.

14. (14) Yelnik A, Bonan I. Clinical tools for assessing balance disorders. Neurophysiol Clin 2008;38(6):439-445.doi:10.1016/j.neucli.2008.09.008

15. (15) Reguera-García MM, de Souza-Teixeira F, de Paz Fernández, Jose Antonio. Test-retest reliability of static postural control in people with multiple sclerosis. J Phys Ther Sci 2017;29(8):13991404.doi:10.1589/jpts.29.1399

16. (16) Kirkland-Walsh $H$, Teleten $O$, Wilson $M$, Raingruber B. Pressure mapping comparison of four $O R$ surfaces. AORN J 2015;102(1):e1-e9.doi:10.1016/j.aorn.2015.05.012

17. (17) Maguiña P, Kirkland-Walsh H. Hospital-Acquired Pressure Ulcer Prevention: A Burn Surgeon's Team Approach. J Burn Care Res 2014;35(5):e287-e293.doi:10.1097/BCR.0000000000000057

18. (18) Folstein MF, Folstein SE, McHugh PR. "Mini-mental state": a practical method for grading the cognitive state of patients for the clinician. J Psychiatr Res 1975;12(3):189-198.doi: 10.1016/00223956(75)90026-6

19. (19) Motamedi S, de Grood J, Harman S, Sargious P, Baylis B, Flemons W, et al. The effect of continuous pressure monitoring on strategic shifting of medical inpatients at risk for PUs. J Wound Care 2012;21(11):517-527.doi:10.12968/jowc.2012.21.11.517

20. (20) Wininger $M$, Crane BA. Prevalence of sensor saturation in wheelchair seat interface pressure mapping. Assist Technol 2015;27(2):69-75.doi:10.1080/10400435.2014.976800 
21. (21) Brauer S, Burns Y, Galley P. Lateral reach: a clinical measure of medio-lateral postural stability. Physiother Res Int 1999;4(2):81-88.doi:10.1002/pri.155

22. (22) Freeman J, Gear M, Pauli A, Cowan P, Finnigan $C$, Hunter $H$, et al. The effect of core stability training on balance and mobility in ambulant individuals with multiple sclerosis: a multi-centre series of single case studies. Mult Scler 2010;16(11):1377-1384.doi:10.1177/1352458510378126

23. (23) Duncan PW, Weiner DK, Chandler J, Studenski S. Functional reach: a new clinical measure of balance. J Gerontol 1990;45(6):M192-M197.doi:10.1093/geronj/45.6.M192

24. (24) Choe HS, Min D, Ahn J. Effects of anterior weight-shifting methods on sitting balance in wheelchair-dependent patients with spinal cord injury. J Phys Ther Sci 2018;30(3):393397.doi:10.1589/jpts.30.393

25. (25) Berg KO, Wood-Dauphinee SL, Williams JI, Maki B. Measuring balance in the elderly: validation of an instrument. Can J Public Health 1992;83:S7-S11.

26. (26) Downs S, Márquez J, Chiarelli P. The Berg Balance Scale has high intra-and inter-rater reliability but absolute reliability varies across the scale: a systematic review. J Physiother 2013;59(2):9399.doi:10.1016/S1836-9553(13)70161-9

27. (27) Rodby-Bousquet E, Agústsson A, Jónsdóttir G, Czuba T, Johansson A, Hägglund G. Interrater reliability and construct validity of the Posture and Postural Ability Scale in adults with cerebral palsy in supine, prone, sitting and standing positions. Clin Rehabil 2014;28(1):8290.doi:10.1177/0269215512465423

28. (28) Rodby-Bousquet E, Persson-Bunke M, Czuba T. Psychometric evaluation of the Posture and Postural Ability Scale for children with cerebral palsy. Clin Rehabil 2016;30(7):697704.doi:10.1177/0269215515593612

29. (29) Gorman SL, Radtka S, Melnick ME, Abrams GM, ByI NN. Development and validation of the Function In Sitting Test in adults with acute stroke. J Neurol Phys Ther 2010 Sep;34(3):150160.doi:10.1097/NPT.0b013e3181f0065f

30. (30) Gorman SL, Rivera M, McCarthy L. Reliability of the Function in Sitting Test (FIST). Rehabil Res Pract 2014;2014:593280.doi:10.1155/2014/593280

31. (31) Duarte E, Marco E, Muniesa J, Belmonte R, Diaz P, Tejero M, et al. Trunk control test as a functional predictor in stroke patients. J Rehabil Med 2002;34(6):267-272.doi: 10.1080/165019702760390356.

32. (32) Berthold J, Dicianno BE, Cooper RA. Pressure mapping to assess seated pressure distributions and the potential risk for skin ulceration in a population of sledge hockey players and control subjects. Disabil Rehabil Assist Technol 2013;8(5):387-391.doi:10.3109/17483107.2013.769123

33. (33) Crawford SA, Stinson MD, Walsh DM, Porter-Armstrong AP. Impact of sitting time on seatinterface pressure and on pressure mapping with multiple sclerosis patients. Arch Phys Med Rehabil 2005;86(6):1221-1225.doi:10.1016/j.apmr.2004.08.010

34. (34) Stinson M, Crawford S, Porter-Armstrong A. Interface pressure measurements: Visual interpretation of pressure maps with MS clients. Disabil Rehabil 2008;30(8):618- 
624.doi:10.1080/09638280701400409

35. (35) Frzovic D, Morris ME, Vowels L. Clinical tests of standing balance: performance of persons with multiple sclerosis. Arch Phys Med Rehabil 2000;81(2):215-221.doi:10.1016/S0003-9993(00)90144-8

36. (36) Kizony R, Raz L, Katz N, Weingarden H, Weiss PLT. Video-capture virtual reality system for patients with paraplegic spinal cord injury. J Rehabil Res Dev 2005;42(5):595-608. doi:

10.1682/jrrd.2005.01.0023

37. (37) Abou L, Sung J, Sosnoff JJ, Rice LA. Reliability and validity of the function in sitting test among non-ambulatory individuals with spinal cord injury. J Spinal Cord Med 2019:1-

8.doi:10.1080/10790268.2019.1605749

38. (38) Sung J, Ousley CM, Shen S, Isaacs ZJ, Sosnoff JJ, Rice LA. Reliability and validity of the function in sitting test in nonambulatory individuals with multiple sclerosis. Int $\mathrm{J}$ Rehabil Res 2016;39(4):308-312.doi:10.1097/MRR.0000000000000188

39. (39) Collin C, Wade D. Assessing motor impairment after stroke: a pilot reliability study. J Neurol Neurosurg Psychiatry 1990;53(7):576-579.doi:10.1136/jnnp.53.7.576

40. (40) Cetisli-Korkmaz N, Can-Akman T, Kilavuz-Oren G, Bir LS. Trunk control: the essence for upper limb functionality in patients with multiple sclerosis. Mult Scler Relat Disord 2018;24:101106.doi:10.1016/j.msard.2018.06.013

41. (41) Quinzaños J, Villa A, Flores A, Pérez R. Proposal and validation of a clinical trunk control test in individuals with spinal cord injury. Spinal Cord 2014;52(6):449-454. doi:10.1038/sc.2014.34

42. (42) Eftekharsadat B, Babaei-Ghazani A, Mohammadzadeh M, Talebi M, Eslamian F, Azari E. Effect of virtual reality-based balance training in multiple sclerosis. Neurol Res 2015;37(6):539-544. doi:10.1179/1743132815Y.0000000013

43. (43) Santos de Oliveira LA, Polonini C, Horsczaruk CHR, Lima DC, Pereira JV, Rocha LF, et al. Decreasing fall risk in spinocerebellar ataxia. J Phys Ther Sci 2015;27(4):12231225.doi:10.1589/jpts. 27.1223

\section{Figures}




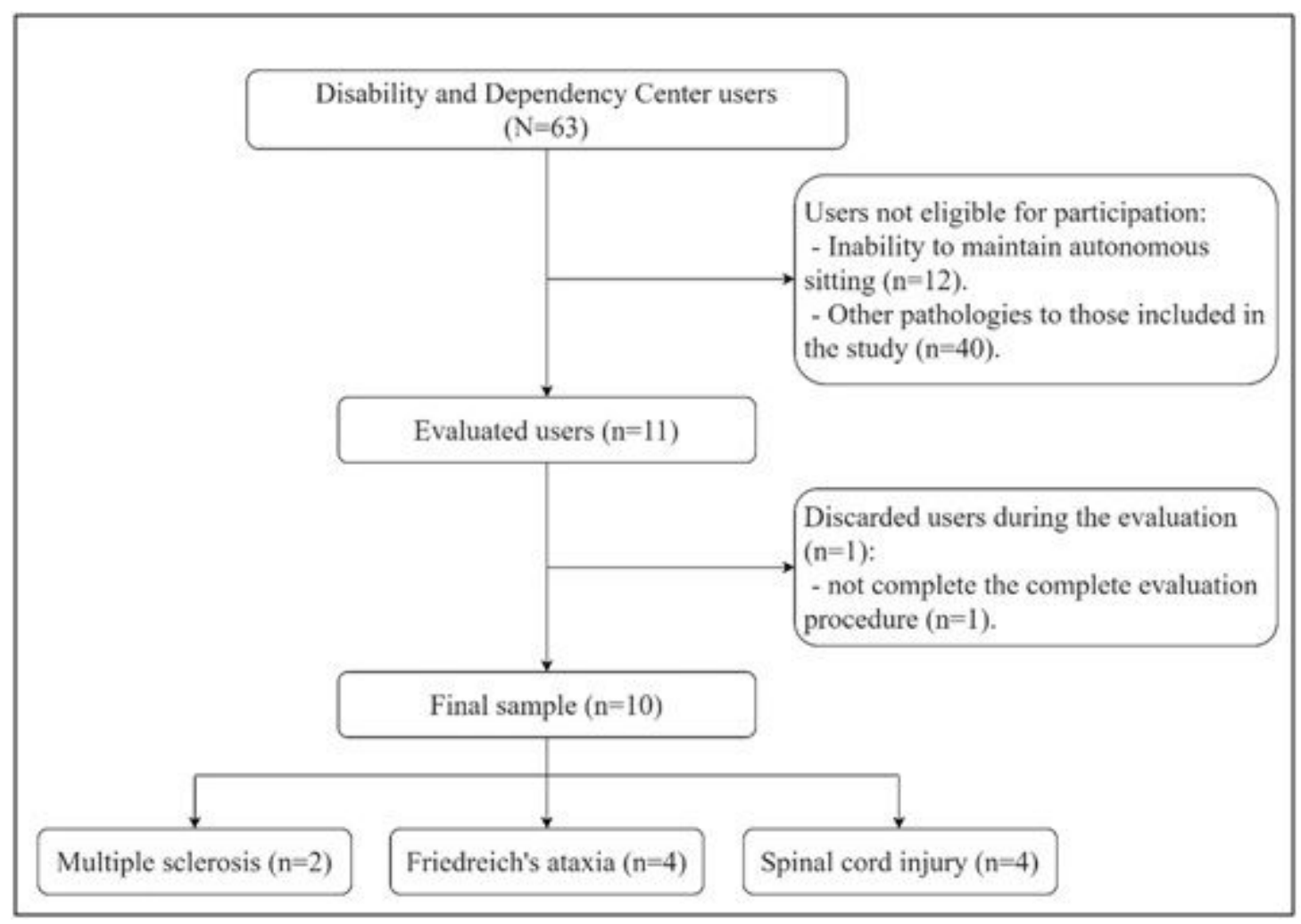

\section{Figure 1}

\section{CONSORT flowchart diagram}

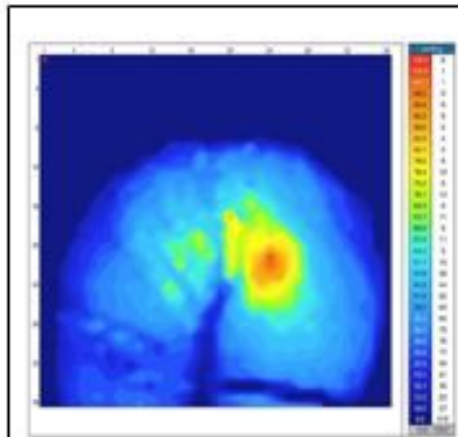

Sclerosis Multiple

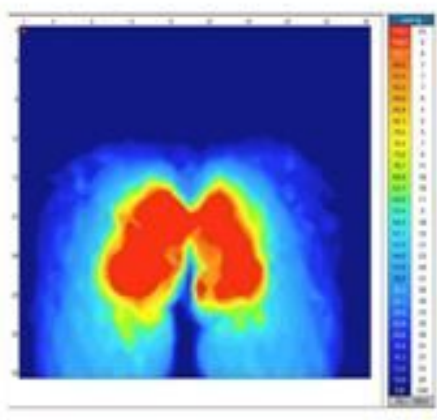

Friedreich's ataxia

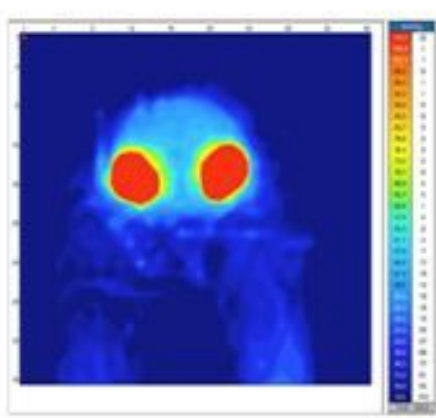

Spinal cord injury

Figure 2

Examples of frames extracted from pressure mapping 